\title{
SISTEMAS DE PRODUÇÃO E CULTIVARES DE FEIJOEIRO EM CONSÓRCIO COM MILHO ${ }^{1}$
}

\section{PRODUCTION SYSTEMS AND BEAN CULTIVARS IN INTERCROPPING WITH MAIZE}

\author{
Denis Santiago da COSTA ${ }^{2}$ \\ Rafael Marani BARBOSA ${ }^{3}$ \\ Marco Eustáquio de $S A^{4}$
}

\begin{abstract}
RESUMO
Visando melhor aproveitamento da área, a utilização de consórcio de culturas pode se tornar alternativa viável para maior lucratividade, principalmente em pequenas propriedades, que têm pequena área e podem explorar a mão de obra familiar. Com o consórcio milho-feijão, o milho pode ser utilizado para o consumo "in natura" e o feijão para consumo próprio ou utilizado como semente para a próxima semeadura. Explorando essa possibilidade, foi conduzido um experimento no período de maio a outubro de 2007, no município de Selvíria-MS, com o objetivo estudar os efeitos de sistemas de consorciação envolvendo arranjo de plantas e alturas de milho sobre o desempenho de quatro cultivares de feijoeiro. $O$ delineamento estatístico foi blocos ao acaso com quatro repetições e esquema fatorial $4 \times 5$ constituído por quatro cultivares de feijoeiro (Carioca Precoce, Colibri, Rubi, IAC Carioca Eté) e cinco sistemas de cultivo (Solteiro, consórcio de uma linha de feijão entre as linhas de milho alto, uma linha de feijão entre as linhas de milho baixo, duas linhas de feijão entre as linhas de milho alto e consórcio com duas linhas de feijão entre as linhas de milho baixo). Concluiu-se que, a produtividade das cultivares foi dependente do sistema de consórcio e também as cultivares de feijoeiro somente diferiram em produtividade quando cultivadas no sistema solteiro ou uma linha de feijão entre o milho de porte baixo. As cultivares Carioca Precoce e Rubi estiveram entre as melhores nos dois sistemas.
\end{abstract}

Palavras-chave: Phaseolus vulgaris; Zea mays; arranjo; porte do milho.

\section{ABSTRACT}

For a better exploitation of the area, the use of culture in intercropping can become a viable alternative to higher profitability, especially in small farms that have small area and can explore the family labor. With the intercropping maizebeans, corn can be used for consumption "in natura" and beans for own consumption or used as seed for the next sowing. Exploring this possibility, an experiment was conducted from May to October 2007, in Selvíria-MS, the objective was to study the effects of intercropping systems involving plant arrangement and size of maize on the performance of four common bean cultivars. The experimental design was a randomized block design with four replications and a factorial $4 \times 5$ made up of four bean cultivars (Carioca Precoce, Colibri, Rubi, IAC Carioca Eté) and five cropping systems (Single, intercropping of a row of beans between rows of tall maize, a row of beans between the rows of short maize, two rows of beans between rows of tall maize and two rows of beans between the rows of small maize). It was concluded that the productivity was dependent on the intercropping system and also the only bean cultivars differed in yield when grown in the single system or a row of beans between maize stature. The cultivars Carioca Precoce and Rubi were among the best in both systems.

Key-words: Phaseolus vulgaris; Zea mays; arrangement; maize size.

\footnotetext{
${ }^{1}$ Parte do projeto de pesquisa desenvolvido com bolsa da FAPESP.

${ }^{2}$ Bolsista FAPESP. Graduando do curso de agronomia UNESP-Ilha Solteira. Endereço: Rua Porto Rico, 961, Vila Esperança, CEP: 13635-103, Pirassununga, SP, Brasil. E-mail: the_denis@hotmail.com

${ }^{3}$ Graduando do curso de agronomia. UNESP, Iha Solteira, SP, Brasil. E-mail: marani_7@hotmail.com

${ }^{4}$ Professor do Curso de Agronomia da UNESP-Ilha Solteira. Departamento de Fitotecnia, Tecnologia de Alimentos e Sócio-Economia. Rua Monção, 230, CEP 15385-000, Ilha Solteira, SP, Brasil .E-mail: mesa@agr.feis.unesp.br
} 
COSTA, D. S. et al. Sistemas de produção e cultivares...

\section{INTRODUÇÃO}

O consórcio é considerado um sistema de cultivo de duas ou mais culturas que realizam a convivência entre si, de modo que parte ou todo seu ciclo é realizado em uma mesma área (Portes \& Silva, 1996).

Sistemas de consórcio entre espécies vegetais que apresentam diferentes arquiteturas de plantas e distintos padrões de crescimento do sistema radicular podem melhorar o aproveitamento dos recursos do meio (água, luz e nutrientes), proporcionando maior acúmulo de massa por área em determinado tempo (Vieira, 1999). Além disso, consórcio contribui para elevar a biodiversidade do agroecossistema, o que pode reduzir a incidência de pragas, doenças e plantas daninhas durante o cultivo (Altieri et al., 2003).

O consórcio milho-feijão é prática generalizada em boa parte das pequenas propriedades do Brasil, nas quais os produtores buscam, com esse sistema, a redução dos riscos de perdas, o melhor aproveitamento da sua propriedade e maior retorno econômico, além de constituir alternativa altamente viável para aumentar a oferta de alimentos (Andrade et al., 2001).

O feijoeiro é uma leguminosa de metabolismo fotossintético $\mathrm{C}_{3}$, ou seja, mostra-se menos eficiente na fixação do $\mathrm{CO}_{2}$ em relação ao milho, que é uma gramínea e apresenta metabolismo fotossintético $\mathrm{C}_{4}$. O sucesso desse consórcio está basicamente nas diferenças apresentadas por ambas as espécies quanto às exigências e tolerâncias. Neste sistema, nota-se competição entre a gramínea e a leguminosa, principalmente em relação à luz, já que a leguminosa apresenta porte bem mais baixo que a gramínea (Vieira, 1999). Uma vez que a radiação afeta o desenvolvimento da cultura de menor porte, a escolha do melhor arranjo e da época de semeadura é crucial no desempenho do sistema, ou seja, na maximização da produção (Flesch, 2002).

Várias indagações ainda são feitas com relação ao consórcio milho-feijão, quando se busca maximizar a eficiência de ambas as culturas. Assim, encontrar cultivares adaptadas aos sistemas de consórcio pode melhorar o desempenho do sistema e a produtividade das culturas consortes.

O objetivo do trabalho foi estudar os efeitos de sistemas de consórcio, envolvendo arranjo de plantas e alturas de milho, sobre o desempenho e produtividade de quatro cultivares de feijoeiro.

\section{MATERIAL E MÉTODOS}

O experimento foi instalado na Fazenda experimental da UNESP, Campus de Ilha Solteira, Selvíria-MS, em solo anteriormente ocupado por vegetação de cerrado e classificado como Latossolo Vermelho Eutrófico típico, argiloso, A moderado, hipodistrófico, álico, caulinítico, férrico, compactado, muito profundo e moderadamente ácido (Lve) (Embrapa, 2006). Os resultados da análise de solos referente ao local de implantação do experimento estão contidos na Tabela 1. A área está situada aproximadamente a $50^{\circ} 57^{\prime} \mathrm{W}$ e $21^{\circ} 44^{\prime} \mathrm{S}$, com altitude de $335 \mathrm{~m}$. O clima é do tipo Aw segundo a classificação de Koëppen, apresentando temperatura média do ar anual de $24,5{ }^{\circ} \mathrm{C}$, precipitação pluviométrica anual de $1370 \mathrm{~mm}$ e umidade relativa média do ar anual de $64,8 \%$ (Hernandez et al., 1995). A área foi manejada em sistema de preparo convencional com uma aração e duas gradagens.

TABELA 1 - Características químicas do solo da área do experimento. Selvíria-MS, 2007.

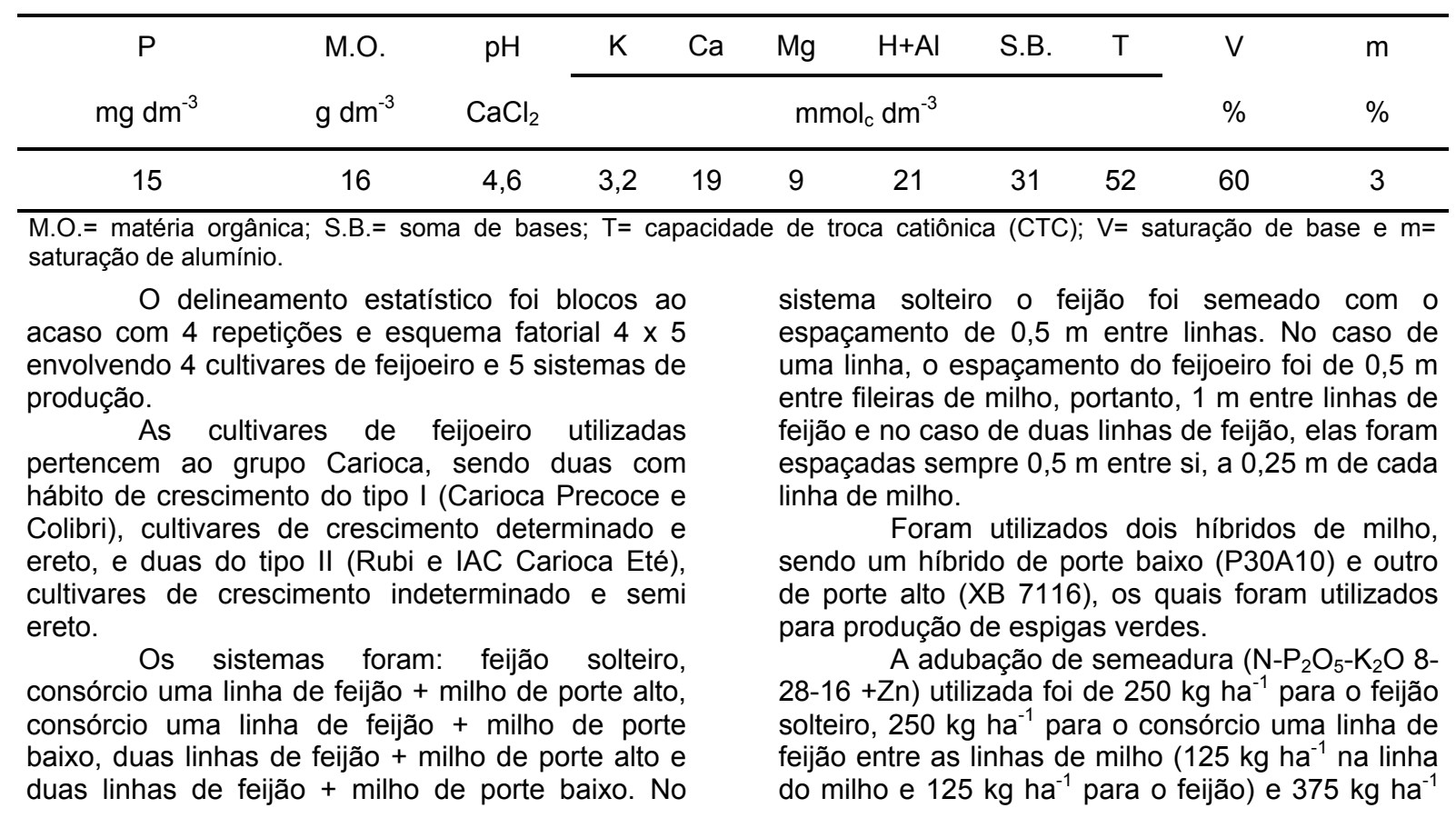


COSTA, D. S. et al. Sistemas de produção e cultivares...

para o consórcio duas linha de feijão entre as linhas de milho (125 kg ha-1 para a linha do milho e $250 \mathrm{~kg}$ $\mathrm{ha}^{-1}$ para as duas linhas de feijão), visando dar condições equivalentes para os diferentes arranjos. A adubação em cobertura foi realizada no estádio fenológico $V_{4-6}$ (feijoeiro com a sexta folha trifoliolada) para o feijoeiro e no estádio $V_{4}$ (milho com a $4^{\text {a }}$ folha totalmente desenvolvida) para 0 milho, aplicando-se $50 \mathrm{~kg} \mathrm{ha}^{-1}$ de $\mathrm{N}$ (fonte uréia).

O experimento foi conduzido no período de inverno com irrigação por aspersão (o turno de rega variava de acordo com a evapotranspiração, sendo que o volume irrigado representava a quantidade de água perdida pela evapotranspiração da cultura). $\mathrm{O}$ milho foi semeado na base de 6 sementes por metro, com objetivo de obter densidade de 5 plantas por metro, enquanto para o feijão foram utilizadas 18 sementes por metro, visando se obter densidade de 15 plantas por metro, exceto para a cultivar Colibri, para a qual se desejava uma densidade final de 18 plantas por metro.

As avaliações realizadas no feijoeiro foram as seguintes:

- Estandes inicial e final - estimados em plantas por hectare a partir da contagem em $2 \mathrm{~m}$ nas duas linhas centrais de cada parcela, determinando-se a densidade e calculando-se de acordo com o espaçamento do feijoeiro;

- Massa seca - avaliada em 10 plantas coletadas aleatoriamente dentro da parcela no estádio R1 (uma flor aberta em $50 \%$ das plantas);

- Número de vagens por planta determinado a partir de amostra de 10 plantas por parcela;
- Número de sementes por vagem determinado na amostra de 10 plantas da avaliação anterior;

- Produção de sementes - estimada a partir da colheita de $2 \mathrm{~m} \times 4 \mathrm{~m}$ de cada parcela, trilha mecânica e pesagem, sendo o resultado expresso em kg ha-1, considerando o grau de umidade de $130 \mathrm{~g} \mathrm{~kg}^{-1}$ b.u. (base úmida);

- Massa de 1000 sementes - estimada a partir de 8 subamostras de 100 sementes por parcela, que foram pesadas em balança de precisão de 0,1 g, de acordo com metodologia descrita nas Regras para Análise se Sementes (Brasil, 2009).

Os dados obtidos foram submetidos à análise da variância. A comparação das médias foi feita pelo teste de Tukey (5\%), utilizando o programa SISVAR (Ferreira, 2000).

\section{RESULTADOS E DISCUSSÃO}

A emergência das plantas ocorreu aos 6 e 10 dias após a semeadura para o milho e para o feijão, respectivamente. Por se tratar de semeadura de inverno a emergência das plântulas atrasou em função da temperatura do solo. As populações inicial e final do feijoeiro variaram de acordo com o sistema de produção e com as cultivares utilizadas. O consórcio de uma linha de feijão entre as linhas de milho, tanto de porte alto como de porte baixo, apresentou menores populações (inicial e final). A menor população nesses dois sistemas é plenamente justificada, pois nestes arranjos havia apenas 1 linha de feijão entre as de milho, o que diminui o número de plantas por hectare (Tabela 2).

TABELA 2 - Média de população de plantas inicial e final, massa seca da parte aérea, altura de planta e altura de inserção da primeira vagem de quatro cultivares de feijoeiro, em cinco sistemas de produção. Selvíria-MS, 2007.

\begin{tabular}{|c|c|c|c|c|c|}
\hline Fator & 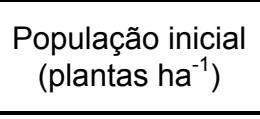 & $\begin{array}{l}\text { População final } \\
\text { (plantas ha }^{-1} \text { ) }\end{array}$ & $\begin{array}{c}\text { Massa } \\
\text { seca } \\
(\mathrm{g}) \\
\end{array}$ & $\begin{array}{c}\text { Altura de } \\
\text { plantas } \\
(\mathrm{cm})\end{array}$ & $\begin{array}{c}\text { Altura de } \\
\text { inserção } \\
(\mathrm{cm})\end{array}$ \\
\hline \multicolumn{6}{|c|}{$\overline{F e i j a ̃ o(F e)}$} \\
\hline Carioca Precoce & $264750 \mathrm{~b}$ & $252625 b$ & 7,67 & $45,3 c$ & $18,14 b$ \\
\hline Colibri & $327250 \mathrm{a}$ & $311125 a$ & 6,81 & $59,8 \mathrm{~b}$ & $21,51 \mathrm{a}$ \\
\hline Rubi & $231375 b$ & $221500 \mathrm{~b}$ & 7,92 & $68,8 \mathrm{a}$ & $20,97 a b$ \\
\hline IAC Carioca Eté & $238500 \mathrm{~b}$ & 227775 b & 7,39 & $61,0 \mathrm{~b}$ & $19,89 a b$ \\
\hline \multicolumn{6}{|c|}{ Consórcio(C) } \\
\hline Solteiro & $318437 a$ & $300000 \mathrm{a}$ & $5,55 \mathrm{~b}$ & $54,07 \mathrm{~b}$ & $19,44 b$ \\
\hline $1 \mathrm{~L}+$ Milho alto & $193750 \mathrm{~b}$ & $185656 \mathrm{~b}$ & $6,87 a b$ & $55,17 a b$ & $20,30 a b$ \\
\hline $1 \mathrm{~L}+$ Milho baixo & $191718 b$ & 184062 b & $8,32 \mathrm{a}$ & $61,32 a b$ & $17,87 \mathrm{c}$ \\
\hline $2 \mathrm{~L}+$ Milho alto & 296562 a & $274062 a$ & $7,90 \mathrm{ab}$ & $61,47 a$ & $21,58 \mathrm{a}$ \\
\hline $2 \mathrm{~L}+$ Milho baixo & 306875 a & $292500 \mathrm{a}$ & $8,61 \mathrm{a}$ & $61,69 a$ & $21,45 a$ \\
\hline \multicolumn{6}{|c|}{ Valores de F } \\
\hline $\mathrm{F}(\mathrm{Fe})$ & $11,806^{*}$ & $11,326^{*}$ & $1,052^{\text {n.s. }}$ & $32,204^{*}$ & $3,073^{*}$ \\
\hline$F(C)$ & $16,012^{*}$ & $18,842^{*}$ & $5,137^{\star}$ & $3,388^{*}$ & $2,715^{\star}$ \\
\hline $\mathrm{F}\left(\mathrm{Fe}^{\star} \mathrm{C}\right)$ & $1,645^{\text {n.s. }}$ & $1,573^{\text {n.s. }}$ & $1,041^{\text {n.s. }}$ & $0,973^{\text {n.s. }}$ & $1,048^{\text {n.s. }}$ \\
\hline C.V.\%(Consórcio) & 25,67 & 23,87 & 29,56 & 14,00 & 18,52 \\
\hline C.V.\%(Feijão) & 21,38 & 21,44 & 27,93 & 13,11 & 18,81 \\
\hline
\end{tabular}

${ }^{*}$ significativo pelo teste $\mathrm{F}$ a $5 \%$ de probabilidade; ${ }^{\text {n.s. }}$ não significativo pelo teste $\mathrm{F}$ a $5 \%$ de probabilidade; C.V.: coeficiente de variação. Médias seguidas de mesma letra na coluna não difere entre si pelo teste de Tukey a $5 \% .1 \mathrm{~L}=$ linhas de feijoeiro espaçadas à $0,5 \mathrm{~m}$ entre fileiras de milho, portanto, $1 \mathrm{~m}$ entre linhas de feijão; $2 \mathrm{~L}=$ linhas de feijoeiro espaçadas sempre 0,5 $\mathrm{m}$ entre si, a $0,25 \mathrm{~m}$ de cada linha de milho. 
COSTA, D. S. et al. Sistemas de produção e cultivares...

Quanto à população de plantas mais adequada ao consórcio, há controvérsias, porém, grande parte dos trabalhos destaca que os maiores rendimentos têm sido obtidos com populações de 40.000 plantas ha ${ }^{-1}$ e 120.000 plantas ha $^{-1}$ para milho e feijão, respectivamente, na época das águas, e de 60.000 plantas $\mathrm{ha}^{-1}$ para o milho e 240.000 plantas ha- ${ }^{1}$ para o feijão comum, na época da seca. (Vieira, 1999; Morgado \& Willey, 2008).

Para altura de plantas observou-se que os feijoeiros consorciados apresentaram maior altura em relação ao sistema de cultivo solteiro (Tabela 2 ). Tal resultado é explicável devido ao fato de que plantas submetidas ao sombreamento tendem a estiolarem-se para buscar a luz solar (Taiz \& Zeigher, 2004).

A altura de inserção da primeira vagem do feijoeiro mostrou variação significativa em função dos sistemas, sendo que os consórcios com duas linhas de feijão apresentaram maiores valores para essa variável.

Também ocorreram variações para altura de planta e altura de inserção da primeira vagem de acordo com as cultivares utilizadas (Tabela 2). Essa variação é causada pelas diferenças genéticas entre cultivares, as quais respondem de forma diferente quando são submetidas a condições adversas.

Quanto à massa de matéria seca, o tratamento feijão cultivado no sistema solteiro apresentou menor valor. Por se tratar de planta $C_{3}$, o feijoeiro pode apresentar alta taxa de fotorrespiração, fazendo com que a conversão de gás carbônico seja baixa quando há ocorrência de altas temperaturas (Taiz \& Zeigher, 2004). O sombreamento causado pelas plantas de milho pode ter resultado em menor temperatura na superfície foliar, que certamente favoreceu o acúmulo de matéria seca. Também não se descarta da hipótese de a maior população de plantas do monocultivo ter influenciado negativamente no acúmulo de matéria seca e deve-se considerar a possibilidade do feijoeiro em consórcio ter utilizado parte do adubo da linha de milho. Santos (2007), em um dos estudos com dois híbridos de milho e quatro cultivares de feijão, observou diferenças de matéria seca entre as cultivares, mas o uso do consórcio não influenciou a quantidade de matéria seca.

O número de vagens planta $^{-1}$ e grãos vagem $^{-1}$ não foram influenciados nem pelas cultivares de feijoeiro, nem pelos sistemas de consórcio estudados (Tabela 3). Entretanto, verificou-se que houve diferenças para a massa de 1000 sementes de acordo com a cultivar utilizada, sendo assim considerada uma característica que varia de acordo com o genótipo utilizado. Também, a utilização dos diferentes sistemas de consórcio afeta a massa de 1000 sementes. Verificou-se que, quanto mais o feijoeiro estava em situação de ausência de competição (solteiro, uma linha de feijoeiro entre os milhos de portes alto e baixo) maior foi a massa de 1000 sementes, quando comparado no sistema que havia maior competição (duas linhas de feijoeiro entre os milhos de portes alto e baixo).

TABELA 3 - Médias de número de vagens.planta ${ }^{-1}$, número de semente.vagem ${ }^{-1}$, massa de 100 sementes e produtividade de grãos de quatro cultivares de feijoeiro comum, em cinco sistemas de produção. Selvíria-MS, 2007.

\begin{tabular}{|c|c|c|c|c|}
\hline Fator & $\begin{array}{l}\text { Número de vagens } \\
\text { planta }^{-1}\end{array}$ & $\begin{array}{l}\text { Número de sementes } \\
\text { vagem }^{-1}\end{array}$ & $\begin{array}{c}\text { Massa de } \\
1000 \\
\text { sementes } \\
(\mathrm{g})\end{array}$ & $\begin{array}{l}\text { Produtividade } \\
\mathrm{kg} \mathrm{ha}^{-1}\end{array}$ \\
\hline \multicolumn{5}{|c|}{ Feijão(Fe) } \\
\hline Carioca Precoce & 8,9 & 4,0 & $232,6 b$ & 1610 \\
\hline Colibri & 7,5 & 3,9 & $232,9 \mathrm{~b}$ & 1266 \\
\hline Rubi & 8,4 & 3,8 & 252,5 a & 1507 \\
\hline IAC Carioca Eté & 8,3 & 3,7 & 246,6 a & 1524 \\
\hline \multicolumn{5}{|c|}{ Consórcio(C) } \\
\hline Solteiro & 8,64 & 4,30 & $248,9 a$ & 1863 \\
\hline $1 \mathrm{~L}+$ Milho alto & 8,07 & 3,83 & $245,6 a b$ & 728 \\
\hline $1 \mathrm{~L}+$ Milho baixo & 8,95 & 4,07 & $247,6 \mathrm{ab}$ & 1357 \\
\hline $2 \mathrm{~L}+$ Milho alto & 7,22 & 4,41 & $231,9 \mathrm{~b}$ & 1473 \\
\hline $2 \mathrm{~L}+$ Milho baixo & 8,60 & 3,60 & $231,8 b$ & 1962 \\
\hline \multicolumn{5}{|c|}{ Valores de $\mathrm{f}$} \\
\hline $\mathrm{F}(\mathrm{Fe})$ & $1,615^{\text {n.s. }}$ & $0,845^{\text {n.s. }}$ & $10,715^{*}$ & $2,311^{\text {n.s. }}$ \\
\hline$F(C)$ & $0,526^{\text {n.s. }}$ & $2,251^{\text {n.s. }}$ & $4,416^{*}$ & $10,602^{*}$ \\
\hline $\mathrm{F}\left(\mathrm{Fe}^{*} \mathrm{C}\right)$ & $1,298^{\text {n.s. }}$ & $1,095^{\text {n.s. }}$ & $1,228^{\text {n.s. }}$ & $2,604^{*}$ \\
\hline C.V.\%(Consórcio) & 25,26 & 21,38 & 6,78 & 24,77 \\
\hline C.V.\%(Feijão) & 24,34 & 15,74 & 5,67 & 24,4 \\
\hline
\end{tabular}

*significativo pelo teste $\mathrm{F}$ a $5 \%$ de probabilidade; ${ }^{\text {n.s. }}$ não significativo pelo teste $\mathrm{F}$ a $5 \%$ de probabilidade; C.V.: coeficiente de variação. Médias seguidas de mesma letra na coluna não diferem entre si pelo teste de Tukey a $5 \%$. $1 \mathrm{~L}=$ linhas de feijoeiro espaçadas à $0,5 \mathrm{~m}$ entre fileiras de milho, portanto, $1 \mathrm{~m}$ entre linhas de feijão; $2 \mathrm{~L}=$ linhas de feijoeiro espaçadas sempre 0,5 $\mathrm{m}$ entre si, a 0,25 $\mathrm{m}$ de cada linha de milho. 
COSTA, D. S. et al. Sistemas de produção e cultivares...

Os resultados obtidos, exceto para a massa de 1000 sementes, concordam com Soares et al. (2000), que em estudos com a cultivar Jalo Precoce em consórcio com milho, não verificaram diferença para número de vagens planta ${ }^{-1}$, grãos vagem $^{-1}$ e massa de 100 grãos em um arranjo de duas fileiras de feijão. Por outro lado, Maciel et al (2004) verificaram que o consórcio interferiu em todas as características agronômicas do feijoeiro e que a mais afetada foi o número de vagens planta $^{-1}$ enquanto as menos afetadas foram o número de grãos vagem ${ }^{-1}$ e a massa de 100 grãos.

A produtividade do feijoeiro foi significativamente influenciada pela interação sistema de consórcio e cultivar. $\mathrm{Na}$ análise do desdobramento da interação observou-se que o feijão Carioca Precoce foi o que mais produziu no sistema solteiro, diferindo do Colibri e IAC Carioca Eté, porém, não diferindo do Rubi. Entretanto, esta cultivar foi também a que mais sofreu com o sistema de consórcio uma linha de feijão entre as linhas de milho (porte alto e baixo), indicando que ela deve ser utilizada em sistema solteiro, ou no sistema de consórcio duas fileiras de feijoeiro entre as linhas do milho de porte baixo (Tabela 4). Costa e Marino (2000) também verificaram que a produtividade do feijoeiro cultivado com uma linha de milho e uma linha de feijão diminui concordando com os dados obtidos para o mesmo esquema de consórcio.

TABELA 4 - Médias de produtividade de grãos $\left(\mathrm{kg} \mathrm{ha}^{-1}\right)$ de quatro cultivares de feijoeiro em cinco sistemas de produção. Selvíria-MS, 2007.

\begin{tabular}{cccccc}
\hline Consórcio/Feijão & Solteiro & 1 L. M. alto & 1 L. M. baixo & 2 L. M. alto & 2 L. M. baixo \\
\hline Colibri & 1254 a B & 860 a A & 860 a B & 1628 a A & 1728 a A \\
Rubi & 1997 a AB & 562 b A & 1568 a AB & 1668 a A & 1739 a A \\
IAC Carioca Eté & 1664 abc B & 865 c A & 1753 ab A & 1144 bc A & 2194 a A \\
\hline
\end{tabular}

Médias seguidas de mesma letra minúscula na linha e maiúscula na coluna não diferem entre si pelo teste de Tukey a $5 \%$. 1 $\mathrm{L}=$ linhas de feijoeiro espaçadas à $0,5 \mathrm{~m}$ entre fileiras de milho, portanto, $1 \mathrm{~m}$ entre linhas de feijão; $2 \mathrm{~L}=$ linhas de feijoeiro espaçadas sempre 0,5 m entre si, a 0,25 m de cada linha de milho.

Alguns autores não tem observado diferenças na produtividade de feijoeiro em função da cultivar ou do porte de milho. Pereira Filho et al. (1991) não observaram efeitos significativos de cultivares de milho sobre o rendimento do feijoeiro. Também, em trabalhos envolvendo cultivares de milho de portes diferentes e feijoeiro, Pereira Filho et al. (2000) verificaram que não houve diferenças de produtividade da leguminosa quanto ao porte da planta de milho. Cruz et al. (1984) avaliaram o comportamento de quinze cultivares de milho (cinco cultivares de porte normal, cinco de porte baixo e cinco precoces), em cultivo solteiro e consorciado na mesma linha com o feijão e concluíram que o menor porte de milho não contribuiu para maior produtividade do feijão associado.

Dornelles et al. (1997), com o objetivo estudar alternativas de arranjos, variando o número de linhas do milho e do feijão, e quatro épocas de semeadura do milho em sistemas consorciados de milho e feijão, verificaram que o feijão consorciado praticamente não apresentou diferenças do monocultivo, diferentemente dos resultados da presente pesquisa onde as cultivares Carioca Precoce, Rubi e IAC Carioca Eté apresentaram comportamento distinto em função do sistema de consórcio utilizado. Para Raposo et al. (1995), os arranjos de plantas influenciam significativamente no rendimento de grãos do milho e feijão consorciados, que tiveram reduções de $18,7 \%$ e $52,2 \%$ em relação aos respectivos cultivos solteiros, concordando, portanto, com o observado no presente trabalho.

\section{CONCLUSÕES}

1) A produtividade das cultivares foi dependente do sistema de consórcio.

2) As cultivares de feijoeiro somente diferiram em produtividade quando cultivadas no sistema solteiro ou uma linha de feijão entre o milho de porte baixo As cultivares Carioca Precoce e Rubi estiveram entre as melhores nos dois sistemas.

\section{REFERÊNCIAS}

1. ALTIEIRI, M.A., SILVA, E.N., NICHOLLS, C.I. O papel da biodiversidade no manejo de pragas. Ribeirão Preto: Holos, 2003. 226 p.

2. ANDRADE, M.J.B.; MORAES, A.R.; TEXEIRA, I.R.; SILVA, M.V.Avaliação de sistemas de consórcio de feijão com milho pipoca. Ciência e Agrotecnologia, v. 25, n. 2, p. 242-250, 2001.

3. BRASIL. Ministério da Agricultura, Pecuária e Abastecimento. Secretaria de Defesa Agropecuária. Regras para análise de sementes. Brasília: Mapa/ACS, 2009.

4. COSTA, J.G.; MARINO, J.T.S. Efeitos de diferentes arranjos no consórcio milho-feijão e milho-caupi no Acre, Brasil. Acta Amazônica, v. 30, n. 3, p. 363-368, 2000.

5. CRUZ, J.C. et al. Avaliação de cultivares de milho associado com feijão. Pesquisa Agropecuária Brasileira, v. 19, n. 2 p. 163-168, 1984.

6. DORNELLES, E.L.B.; MENDEZ, M.G.; CORREA, L.A.V.; SCHUCH, L.O.B. Arranjos de plantas e épocas de semeadura no cultivo consorciado de feijão (Phaseolus vulgaris L.) e milho (Zea mays L.) na região sul do Rio Grande do Sul. Revista Brasileira de Agrociência, v. 3, n. 1, p. 11-16, 1997. 
COSTA, D. S. et al. Sistemas de produção e cultivares...

7. EMBRAPA. Centro Nacional de Pesquisa de Solos. Sistema brasileiro de classificação de solos. 2. ed. Rio de Janeiro, 2006. 306 p.

8. FERREIRA, D.F. Análises estatísticas por meio do Sisvar para Windows versão 4.0. In: REUNIÃO ANUAL DA REGIÃO BRASILEIRA DA SOCIEDADE INTERNACIONAL DE BIOMETRIA, 45., 2000, São Carlos. Anais... São Carlos: UFSCar, 2000. p. 255-258,

9. FLESCH, R.D. Efeitos temporais e espaciais no consórcio intercalar de milho e feijão. Pesquisa Agropecuária Brasileira, v. 37, n. 1, p. 51-56, 2002

10. HERNANDEZ, F.B.T.; LEMOS FILHO, M.A.F., BUZETTI, S. Software hidrisa e o balanço hídrico de llha Solteira. Ilha Solteira: Faculdade de Engenharia- Área de Hidráulica e Irrigação.1995. 45 p.

11. MACIEL, A.D.; ARF, O.; SILVA, M.G.; SÁ, M.E.; RODRIGUES, R.A.F.; BUZETTI, S.; BIANCHINI SOBRINHO, E. Comportamento do feijoeiro em cultivo consorciado com milho em sistema de plantio direto. Acta Scientiarum Agronomy, v. 26, n. 3, p. 273-278, 2004.

12. MORGADO, L. B.; WILLEY, R. W. Optimum plant population for maize-bean intercropping system in the Brazilian semiarid region. Scientia Agricola, v. 65, n. 5, p. 474-480, 2008

13. PEREIRA FILHO, I.A.; OLIVEIRA, A. C.; CRUZ, J.C. Sistema de plantio de milho em fileiras duplas e simples em consórcio com o feijoeiro comum. Pesquisa Agropecuária Brasileira, v. 35, n. 5, p. 951-957, 2000.

14. PEREIRA FILHO, I.A; CRUZ, J.C; RAMALHO, M.A.P.; Produtividade e índice de espiga de três cultivares de milho em sistema de consórcio com feijão comum. Pesquisa Agropecuária Brasileira, v. 26, n. 5 p. 745-751, 1991.

15. PORTES, T. A.; SILVA, C.C. Cultivo consorciado In: ARAÚJO, R.S.; RAVA, C.A.; STONE, L.F.; ZIMMERMANN, M.J. de O. (Coords.). A cultura do feijoeiro comum no Brasil. Piracicaba: Potafós, 1996. p. 619-638.

16. RAPOSO, J.A. A. SCHUCH, L.O.B.; ASSIS, F.N.; et al. Consórcio de milho e feijão em diferentes arranjos e populações de plantas, em Pelotas, RS. Pesquisa Agropecuária Brasileira, v. 30, n. 5, p. 639-647, 1995.

17. SANTOS, N.C.B. Comportamento de cultivares de feijoeiro e milho verde em cultivo solteiro e consorciado. 2007. 97 f. Tese (Doutorado em Agronomia - Sistemas de Produção), Curso de Pós Graduação em Sistemas de Produção. UNESP, Ilha Solteira, 2007.

18. SOARES, D.M.; DEL PELOSO, M.J.; KLUTHCOUSKI, J.; GANDOLFI, L.C.;FARIA, D.J. de. Tecnologia para o sistema consórcio de milho verde com feijão no plantio de inverno. Santo Antônio de Goiás: Embrapa Arroz e Feijão, 2000. 51 p. (Embrapa Arroz e Feijão. Boletim de Pesquisa, 10).

19. TAIZ, L.; ZEIGER, E. Fisiologia vegetal. Porto Alegre: Artmed, 2004. p. 449-484.

20. VIEIRA, C. Estudo monográfico do consórcio milho-feijão no Brasil. Viçosa: Universidade Federal de Viçosa, 1999. $183 \mathrm{p}$.

Recebido em 21/10/2009

Aceito em 20/12/2010 